\title{
AL-IQTISHADIYAH
}

Jurnal Ekonomi Syariah dan Hukum Ekonomi Syariah

E-ISSN: 2621-0274; P-ISSN: 2442-2282

Volume 6, Nomor 2, JDesember 2020

\section{PENGARUH DANA ZAKAT, INFAQ DAN SHODAQOH (ZIS) TERHADAP TINGKAT KEMISKINAN SEBAGAI VARIABEL INTERVENING TAHUN 2015-2019}

\author{
Debi Novalia ${ }^{1}$, Rinol Sumantri ${ }^{2}, \&$ Maya Panorma ${ }^{3}$ \\ Fakultas Ekonomi dan Bisnis Islam, Universitas Islam Negeri Raden Fatah, Indonesia. E-mail: \\ debi.novrendi04@gmail.com ${ }^{1}$; rinolsumantrimei uin@radenfatah.ac.id $^{2}$; maya.izuddin@gmail.com ${ }^{3}$
}

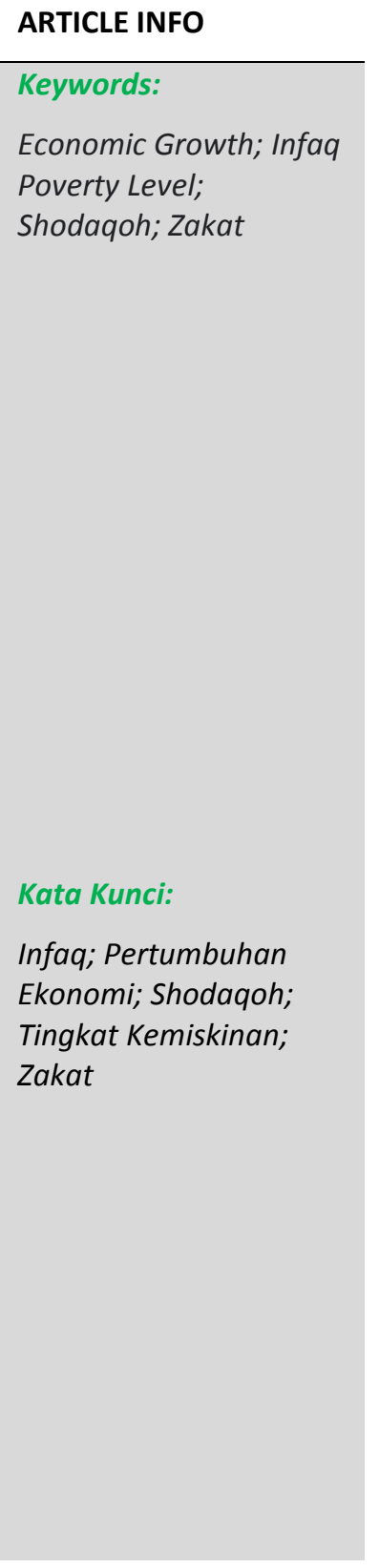

\section{ABSTRACT}

This study aims to determine the relationship between Zakat, Infaq and Shodaqoh Funds on Indonesian Economic Growth and Poverty Levels in the 5 year period, namely between 2015-2019. This study uses quantitative methods with multiple linear regression analysis. Determination of the number of samples using non-probability sampling with saturated samples, that the entire population is used as a sample. The data used are secondary data. The results of this study indicate that the distribution of Zakat, Infaq, Shadaqah Funds has a negative effect on the Poverty Level, the magnitude of the influence of ZIS Fund Distribution on the Poverty Level $=-0.023$ or $2.3 \%$ with a significance level of $0.057>\alpha=0.05$, while the distribution of ZIS funds has a positive effect on Economic growth. The magnitude of the influence of Economic Growth $=0.247$ or $24.70 \%$ with a significance level of $0.047<\alpha=0.05$. Poverty level has a negative effect on economic growth. The magnitude of the influence of the poverty rate on economic growth $=-0.020$ or $-2 \%$ with a significance level of $0.023<\alpha=0.05$. Poverty Level mediates the influence of the ZIS Fund on Economic Growth. economic growth in the aggregate

\section{ABSTRAK}

Penelitian ini bertujuan untuk mengetahui hubungan antara Dana Zakat, Infaq dan Shodaqoh terhadap Pertumbuhan Ekonomi Indonesia dengan Tingkat Kemiskinan dalam kurun waktu 5 tahun yakni antara 2015-2019. Penelitian ini menggunakan metode kuantitatif dengan analisi regresi linier berganda. Penentuan jumlah sampel menggunakan non probability sampling dengan sampel jenuh, bahwa seluruh populasi dijadikan sebagai sampel. Data yang digunakan adalah data sekunder. Hasil dari penelitian ini menunjukkan bahwa Penyaluran Dana Zakat, Infaq, Shadaqah berpengaruh negatif terhadap Tingkat Kemiskinan, besar pengaruh Penyaluran Dana ZIS terhadap Tingkat Kemiskinan $=-0.023$ atau $2.3 \%$ dengan angka signifikansi $0.057>\alpha=0.05$, sedangkan Penyaluran Dana ZIS berpengaruh Positif terhadap Pertumbuhan Ekonomi. Besarnya pengaruh Pertumbuhan Ekonomi $=0.247$ atau $24.70 \%$ dengan angka signifikansi $0.047<\alpha=0.05$. Tingkat Kemiskinan berpengaruh negatif terhadap Pertumbuhan Ekonomi. Besarnya pengaruh Tingkat Kemiskinan terhadap Pertumbuhan Ekonomi = - 
0.020 atau $-2 \%$ dengan angka signifikansi $0.023<\alpha=0.05$. Tingkat Kemiskinan memediasi pengaruh antara Dana ZIS terhadap Pertumbuhan Ekonomi. pertumbuhan ekonomi secara agregat.

\section{Pendahuluan}

Setiap Negara pasti memiliki keinginan untuk menjadi maju, baik dalam bidang pembangunan maupun kesejahteraan masyarakat, setiap Negara juga mengharapkan kemiskinan untuk dapat segera terselesaikan begitupun Indonesia. Menurut Abdul Ghani mendefinisikan bahwa pertumbuhan ekonomi sebagai perkembangan atau peralihan yang terus merangkum peningkatan sumber kekayaan, perkembangan ataupun peralihan dari masa pertanian ke masa industri dan menuju tingkatan kesejahteraan. Dimana setiap rakyat di negara tersebut mampu memenuhi kebutuhan hidup sehari hari dan mencapai pada tingkat sejahtera. ${ }^{1}$

Salah satu cara untuk menentukan pembangunan ekonomi berjalan dengan baik atau tidak yaitu dengan melihat perkembangan ekonomi. Menurut Sukirno bahwa pertumbuhan ekonomi adalah proses peningkatan output perkapita yang terus menerus dalam jangka waktu yang lama. Semakin tinggi kenaikan tingkat pertumbuhan ekonomi maka secara tidak langsung berpengaruh positif terhadap perekonomian masyarakat.

Tabel 1. Pertumbuhan Ekonomi Indonesia tahun 2015-2019 (\%)

\begin{tabular}{cc}
\hline TAHUN & Pertumbuhan Ekonomi (Persen) \\
\hline 2015 & 4.79 \\
\hline 2016 & 5.02 \\
\hline 2017 & 5.07 \\
\hline 2018 & 5.17 \\
\hline 2019 & 5.02 \\
\hline
\end{tabular}

Sumber: Badan Pusat Statistik, 2019

Berdasarkan data terlampir diatas dapat dilihat keadaannya bahwa pertumbuhan ekonomi Indonesia selama 5 tahun terakhir mengalami penurunan yang disebabkan oleh beberapa faktor seperti sumber daya manusia, sumber daya alam, ilmu pengetahuan tekhnologi dan budaya.

Islam mengartikan pertumbuhan ekonomi merupakan perkembangan yang berkelanjutan dari faktor produksi secara jelas yang mampu memberikan manfaat terhadap kesejahteraan umat.

Dalam pandangan ekonomi Islam terdapat beberapa faktor yang mempengaruhi pertumbuhan ekonomi seperti penyaluran dana Zakat, Infaq, dan Shodaqoh. Menurut Riyandono agama Islam mewajibkan untuk mengeluarkan zakat, yang berfungsi

${ }^{1}$ Abdul Ghani Samsudin. Pembangunan Ekonomi Islam : Perspektif Malaysia.2004 
sebagai memaksa seseorang untuk menjadikan hartanya agar senantiasa produktif atau selalu berputar. ZIS (Zakat, Infaq, Shadaqah) salah satu faktor yang dapat meningkatkan pertumbuhan ekonomi dengan cara mengentaskan kemiskinan. ${ }^{2}$

Indonesia adalah negara yang memiliki penduduk muslim mayoritas yaitu sekitar 216.66 juta penduduk dengan jumlah penduduk 85 juta jiwa (menurut BPS 2018). Fakta ini menjelaskan bahwa zakat memiliki potensi untuk berkembang jadi lebih baik lagi. Dan data ini juga menjelaskan bahwa zakat sangat memiliki potensi besar dan berkontribusi dalam mengentaskan kemiskinan. Berikut adalah data jumlah pengumpulan dana Zakat, Infaq dan Shodaqoh di Indonesia pada tahun 2015-2019

Tabel 2. Penyaluran Dana ZIS di Indonesia Tahun 2015-2019

\begin{tabular}{ccc}
\hline Tahun & Penyaluran dana ZIS (Triliun) & Persen (\%) \\
\hline 2015 & $5,017,29$ & 37.2 \\
\hline 2016 & $6,011,53$ & 20.4 \\
\hline 2017 & $8,997,00$ & 38.3 \\
\hline 2018 & $8,100,00$ & 31.8 \\
\hline 2019 & $196,898,00$ & 54.0 \\
\hline
\end{tabular}

Sumber :www.baznas.go.id

Data diatas menunjukkan perkembangan dana ZIS selama lima tahun terhitung sejak 2015 sampai 2019 yang mengalami gelombang naik dan turun. Namun pada tahun 2019, penyaluran dana ZIS mengalami peningkatan yang sangat drastis sebesar $54 \%$.

Semakin tinggi tingkat penyaluran dana ZIS maka akan berdampak terhadap kemajuan perekonomian Indonesia seperti berkurangnya angka kemiskinan, juga dapat memutar roda kegiatan ekonomi masyarakat dengan meningkatnya permintaan dan penawaran barang dan jasa. Perintah mengenai penunaian zakat, infaq dan shodaqoh telah dijelaskan didalam Al-Qur'an dan hadits harus dilakukan sesuai dengan yang telah disyariatkan dan diberikan kepada golongan yang berhak menerimanya atau tergolong kedalam delapan ashnaf diantaranya Fakir, Miskin, Amil, Muallaf, Riqab, Gharim, Fisabilillah dan Ibnusabil.

Berdasarkan fenomena diatas, perbedaan hasil beberapa penelitian terdahulu yang penulis rangkum sebagai berikut juga mempengaruhi penulis melakukan penelitian ini. Raisa Aribatul dalam tesis yang berjudul "Pengaruh Penyaluran Dana Zakat, Infak dan Sedekah (ZIS) dan LKS terhadap Pertumbuhan Ekonomi" menemukan bahwa ZIS berpengaruh Positif signifikan terhadap variabel pertumbuhan ekonomi.

Penelitian lainnya adalah penelitian oleh Ely Kusuma (2012) mengenai Pengaruh Pendidikan Dan Kemiskinan Terhadap Pertumbuhan Ekonomi Di Indonesia yang

\footnotetext{
${ }^{2}$ Ali, Muhammad Daud. Sistem Ekonomi Islam: Zakat dan Wakaf. Jakarta: Ulpress. 1988, hlm. 2
} 
menemukan hasil bahwa variabel kemiskinan tidak berpengaruh signifikan terhadap pertumbuhan ekonomi di Indonesia.

Berbeda dengan hasil penelitian dari Andi Dewi (2015) yang meneliti mengenai Pengaruh Pengangguran dan Kemiskinan Terhadap Pertumbuhan Ekonomi Di Sulawesi Selatan menemukan bahwa pada variabel kemiskinan berpengaruh negatif dan signifikan pada pertumbuhan ekonomi Provinsi Sulawesi Selatan.

Berdasarkan penelian terdahulu terdapat perbedaan hasil penelitian hubungan antara pengaruh variabel dana ZIS dan Variabel Tingkat Kemiskinan terhadap pertumbuhan ekonomi. Perbedaan yang akan diteliti oleh penulis dari penelitihan terdahaulu adalah menambahkan variabel tingkat kemiskinan dijadikan sebagai intervening. Oleh sebab itu penulis tertarik untuk mengangkat judul Pengaruh Dana Zakat, Infaq dan Shodaqah (ZIS) Terhadap Pertumbuhan Ekonomi di Indonesia dengan Tingkat Kemiskinan sebagai Variabel Intervening Periode 2015-2019.

\section{Landasan Teori}

\subsection{Pengertian Zakat}

Zakat merupakan kewajiban yang penting dalam ajaran Islam. Secara etimologi, zakat berarti berkembang (an-namaa), mensucikan (atthaharatu) dan berkah (al-barakatu). Sedangkan secara terminologi, zakat diartikan mengeluarkan sebagian harta dengan syarat tertentu dan diberikan kepada kelompok tertentu (mustahik) dengan persyaratan tertentu pula. ${ }^{3}$

Al-qardawi dari perspektif sosiologis, menyatakan dana zakat akan membantu orang yang menerimanya (mustahik). ${ }^{4}$ Zakat akan mengentaskan kemiskinan serta meminimalisir kesenjangan sosial yang sering terjadi dalam lingkungan masyarakat. Dengan demikian, diharapkan agar tidak terlihatnya perbedaan kelompok antara golongan elit dan golongan bawah. Tujuan utama membayar zakat ialah sebagai solusi untuk menyelesaikan permasalahan ekonomi terutama pengangguran dan kemiskinan. Dengan adanya zakat semua permasalahan tersebut dapat diatasi apabila penyaluran dana zakat tepat sasaran.

\subsection{Pengertian Infaq}

Menurut hasan zakat dan infak adalah kumpulan harta yang disatukan dari para muzaki (wajib zakat) dan dermawan, yang akan dibagikan kembali. ${ }^{5}$ Menurut Hafidhuddin infak merupakan turunan dari anfaqa yang bermakna mengeluarkan harta untuk suatu kepentingan. Infak secara terminologi bermakna mengeluarkan sebagian dari harta atau pendapatan untuk menunaikan kepentingan yang

\footnotetext{
${ }^{3}$ Inayah, Gazi. 2003. Teori Komprehensif Tentang Zakat dan Pajak. Yogyakarta: Tiara Wacana Yogya, hlm. 78

${ }^{4}$ Yusuf Qardhawi, Fiqih Zakat . Beirut: Muassasah ar Risalah 2005. Spektrum Zakatdalam Membangun Ekonomi Kerakyatan. Jakarta: Zikrul Media Intlektual Terjemahan Sari Natulita, Lc, 2000, hlm. 89

${ }^{5}$ Ibid
} 
diperintahkan oleh agama bagi orang yang beriman tanpa melihat ada atau tidaknya penghasilan yang dihasilkan dari individu.

\subsection{Pengertian Shadaqoh}

Menurut Hafidhuddin sedekah berasal dari kata shadaqa yang berarti "benar" orang yang rajin menyedekahkan hartanya adalah orang yang benar-benar beriman kepada Allah SWT. Secara terminologi shodaqoh bermakna yang sama seperti infak, termasuk jugadalil dan syarat-syaratnya.tetapi , jika infak hanya berhubungan dengan materi, sedangkan shodaqoh bersifat luas atau apapun boleh disedekahkan baik berupa materi maupun tidak.

Menurut Qordawi dalam riyandono mengatakan " shodaqoh itu adalah zakat dan zakat itu adalah shodaqoh"memiliki perbedaan sebutan namun bermakna sama namun yang menjadi pembeda antara keduanya ialah terletak pada hokum dimana zakat diwajibkan sedangkan shodaqoh tidak diwajibkan. Shodaqoh termasuk dalam kategori zakat namun zakat tidak dapat dikategorikan sebagai shodaqoh, selain itu juga kewajiban zakat harus ditunaikan setiap tahunnya sedangkan shodaqoh tidak ada batasan waktu yang mewajibkannya.

\subsection{Pertumbuhan Ekonomi}

Menurut Simon Kuznet pertumbuhan ekonomi merupakan suatu proses kenaikan kapasitas dalam jangka waktu panjang dalam suatu negera serta menyediakan berbagai kebutuhan ekonomi masyarakat. Kenaikan kapasitas tersebut ditentukan oleh adanya kemajuan tekhnologi, kelmbagaan dan ideologis terhadap tuntutan keadaan.

\subsection{Tingkat Kemiskinan}

Kemiskinan adalah suatu penyakit dalam perekonomian yang paling sulit untuk dituntaskan karena dapat menyebabkan individu kesulitan dalam memenuhi kebutuhan hidupnya. Ada banyak faktor yang memicu terjadinya kemiskinan setiap individu seperti rendah taraf hidup masyarakat, rendahnya rasa percaya diri serta terbebas kebebasan. Ketiga aspek ini memiliki hubungan timbale balik. Rendahnya taraf hidup dapat dipicu oleh rendahnya tingkat pendapatan yang dipengaruhi rendahnya tingkat produktivitas tenaga kerja. Disisi lain pemicu rendahnya produktivitas ialah tingginya pertumbuhan kerja yang disebabkan oleh tingginya tingkat pengangguran serta rendahnya investasi perkapita.

Dengan demikian pemicu terjadinya kemiskinan dapat juga dipengaruhi oleh aspekaspek sosial dan kelembagaan. Terjadinya kemiskinan dalam suatu kelompok masyarakat sangat berkaitan dengan status sosial ekonomi dan potensi dalam suatu wilayah.

\subsection{Pengembangan Hipotesis}

H1 : Penyaluran dana ZIS berpengaruh negatif terhadap Tingkat Kemiskinan

H2 : Penyaluran Zakat,Infaq, Shadaqah berpengaruh Positif terhadap

H3 : Tingkat Kemiskinan berpengaruh negatif terhadap pertumbuhan ekonomi 
H4 : Tingkat Kemiskinan memediasi pengaruh penyaluran dana ZIS terhadap pertumbuhan ekonomi

\section{Metode Penelitian}

Penelitian ini merupakan penelitian kuantitatif. Penelitian ini terdiri atas tiga variabel yaitu dana ZIS sebagai variabel $X$, Pertumbuhan Ekonomi sebagai variabel $Y$ dan tingkat kemiskinan sebagai variabel Z. Sumber data dalam penelitian ini adalah data sekunder.

Metode analisis data dalam penelitian ini menggunakan analisis deskriptif kuantitatif. Penelitian ini akan menggunakan teknik analisis jalur (path analysis) dengan bantuan program SPSS. Sedangkan teknik analisis yang digunakan dalam penelitian ini adalah teknik analisa uji asumsi klasik yang terdiri atas : uji normalitas, autokolerasi dan uji heterokedastisitas.

\section{Hasil dan Pembahasan}

\subsection{Statistik Deskriptif Variabel}

Analisis Deskriptif Variabel Dana Zakat, Infaq dan Shadaqah (ZIS) Terhadap Pertumbuhan Ekonomi Sumatera Selatan Yang Dimediasi Oleh Variabel Tingkat Kemiskinan Periode

Tabel 3. Descriptive Statistics

\begin{tabular}{lccccc}
\hline & N & Minimum & Maximum & Mean & Std. Deviation \\
\hline ZIS & 60 & 22.92 & 29.00 & 27.1936 & .86948 \\
\hline P EKONOMI & 60 & 1.57 & 1.72 & 1.6265 & .04917 \\
\hline T KEMISKINAN & 60 & 10.23 & 10.59 & 10.4182 & .10459 \\
\hline Valid N (listwise) & 60 & & & & \\
\hline
\end{tabular}

Sumber: Data diolah (2019)

Dari tabel di atas menunjukkan jumlah data yang digunakan dalam penelitian ini berjumlah 60 data dengan penjelasan hasil sebagai berikut:

1. Dana Zakat, Infaq dan Shadaqah (ZIS) menunjukkan nilai minumumnya sebesar 22.92 dan maksimumnya 29.00 dengan standar deviasi 0.86948 , sedangkan mean (rata-rata) sebesar 27.1936 artinya dari semua sampel rata-rata profitabilitasnya adalah 27.1936.

2. Pertumbuhan Ekonomi Sumatera Selatan menunjukkan nilai minimum sebesar 1.57 dan maksmimumnya 1.72 dengan standar deviasi 0.4917 , sedangkan mean (rata-rata) sebesar 1.6265 artinya dari semua sampel rata-rata likuiditasnya adalah 1.6265 . 
3. Tingkat Kemiskinan menunjukkan nilai minimum sebesar 10.23 dan maksimumnya 10.59 dengan standar deviasi 0.10459, sedangkan mean (ratarata) sebesar 10.4182 artinya dari semua sampel rata-rata yield obligasinya adalah 10.4182 .

\subsection{Uji Normalitas}

Tabel 4. Uji Normalitas dengan Jarque Bera

\begin{tabular}{lccccc}
\hline & $\mathbf{N}$ & \multicolumn{2}{c}{ Skewness } & \multicolumn{2}{c}{ Kurtosis } \\
\cline { 2 - 6 } & Statistic & Statistic & Std. Error & Statistic & Std. Error \\
\hline Unstandardized Residual & 60 & .113 & .309 & -1.159 & .608 \\
\hline Unstandardized Residual & 60 & .710 & .309 & -.401 & .608 \\
\hline Valid N (listwise) & 60 & & & & \\
\hline & Sumber: Data diolah (2019)
\end{tabular}

Tabel 5. Hasil Perhitungan Jarque Bera

\begin{tabular}{cc}
\hline Persamaan & Jarque Bera \\
\hline Persamaan I & 20.28 \\
\hline Persamaan II & 21.90
\end{tabular}

1. Persamaan I menyatakan bahwa nilai Jaque Bera sebesar 20.28 , nilai ini ketika dibandingkan dengan $c^{2}$ tabel dengan $d f$ hitung $=(n-k)$. Df $=(60-1)=59$ dan tingkat signifikansi 0.05 maka nilai $c^{2}$ tabel 77.93. Nilai JB $=20.28\left(c^{2}\right.$ hitung $)<77.93\left(c^{2}\right.$ tabel), yang berarti bahwa nilai residual yang terstandarisasi pada persamaan I dinyatakan berdistribusi normal.

2. Persamaan II menyatakan bahwa nilai Jaque Bera sebesar 21.90, nilai ini ketika dibandingkan dengan $c^{2}$ tabel dengan df hitung $=(n-k)$. Df $=(60-2)=58$ dan tingkat signifikansi 0.05 didapat nilai $c^{2}$ tabel 76.78 . Nilai $J B=21.90\left(c^{2}\right.$ hitung $)<76.78$ ( $\mathrm{c}^{2}$ tabel) yang berarti bahwa nilai residual yang tersandarisasi pada persamaan II dinyatakan berdistribusi normal.

\subsection{Uji Linieritas}

Tabel 6. Uji Linieritas dengan Model Lagrange Multiplier

\begin{tabular}{cc}
\hline \multicolumn{2}{c}{ Model Summary } \\
\hline R Square \\
\hline Persamaan I & 0.969 \\
\hline Persamaan II & 0.019 \\
\hline Sumber: Data diolah (2019)
\end{tabular}

1. Hasil output uji linieritas dengan model lagrange multiplier menunjukkan nilai $\mathrm{R}$ Square pada persamaan I sebesar 0.969. Dengan jumlah data (n) observasi 
sebanyak 60 , maka pada persamaan I nilai $c^{2}$ adalah $60 \times 0.969=58.14$. Sedangkan nilai $c^{2}$ tabel dengan $D f=(60-1)=59$ dan tingkat signifikansi 0.05 maka nilai $c^{2}$ tabel 77.93. Nilai $L M=58.14$ ( $c^{2}$ hitung) $<77.93\left(c^{2}\right.$ tabel), yang berarti bahwa model yang benar adalah model linier.

2. Hasil output uji linieritas dengan model lagrange multiplier menunjukkan nilai $\mathrm{R}$ Square pada persamaan II sebesar 0.019. sebanyak 60 , maka pada persamaan II nilai $c^{2}$ adalah $60 \times 0.019=1.14$. Sedangkan nilai $c^{2}$ tabel dengan $\mathrm{Df}=(60-2)=58$ dan tingkat signifikansi 0.05 maka nilai $c^{2}$ tabel 76.78. Nilai $L M=1.14$ ( $c^{2}$ hitung) < 76.78 ( $c^{2}$ tabel), yang berarti bahwa model yang benar adalah model linier.

\subsection{Uji Multikolinieritas}

Tabel 7. Uji Multikolinieritas dengan model Tolerance (TOL) dan Variance Inflation Factor (VIF)

\begin{tabular}{|c|c|c|c|c|}
\hline \multirow[t]{4}{*}{ Coefficients $^{2}$} & & & & \\
\hline & \multicolumn{4}{|c|}{ Collinearity Statistics } \\
\hline & \multicolumn{2}{|c|}{ Persamaan I } & \multicolumn{2}{|c|}{ Persamaan II } \\
\hline & Tolerance 1 & VIF & Tolerance 1 & VIF \\
\hline ZIS & 1.000 & 1.000 & 1.000 & 1.000 \\
\hline
\end{tabular}

Sumber: Data diolah (2019)

Berdasarkan tabel di atas dilihat bahwa nilai tolerance persamaan I dan II menunjukkan semua variabel independen $>0.10$ dan dengan nilai VIF dari semua variabel independen $<10.00$ sehingga dapat disimpulkan bahwa tidak terjadi multikolinieritas.

\subsection{Uji Autokolerasi}

Uji Autokolerasi dengan menggunakan metode Durbin-Watson Test dapat mengidentifikasi adanya korelasi antar variabel itu sendiri.

Tabel 8. Tabel Autokolerasi dengan Durbin Watson

\begin{tabular}{ccc|}
\hline Durbin Watson & & \\
\hline Model & Persamaan I & Persamaan II \\
\hline 1 & 0.747 & 0.156 \\
\hline
\end{tabular}

Sumber: Data diolah (2019)

Berdasarkan data pada tabel 8 diketahui DW pada persamaan I sebesar 0.747 dan nilai DW pada persamaan II sebesar 0.156 Berdasarkan kriteria pengambilan keputusan bahwa apabila nilai DW antara -2 sampai +2 berarti tidak terjadi autokorelasi. 


\subsection{Uji Heterokedastisitas}

Uji heteroskedastisitas menggunakan model Uji Glejser, yang menyatakan bahwa apabila nilai $c^{2}$ hitung $<c^{2}$ tabel maka dapat dipastikan model tidak mengandung gejala heteroskedastisitas.

Tabel 9. Tabel Heteroskedastisitas dengan Uji Glejser

\begin{tabular}{cc}
\hline Model Summary & R Square \\
\hline & 0.081 \\
\hline Persamaan I & 0.147 \\
\hline
\end{tabular}

Sumber: Data diolah (2019)

Berdasarkan tabel 9 diketahui bahwa :

1. Pada persamaan I nilai $R$ Square sebesar 0.081 dengan jumlah data observasi sebanyak 60 , maka besarnya nilai $c^{2}$ hitung $=60 \times 0.081=4,86$, Sedangkan nilai $c^{2}$ tabel dengan $\mathrm{Df}=(60-1)=59$ dan tingkat signifikansi 0.05 maka nilai $c^{2}$ tabel 77.93. Jadi nilai uji glejser $=26.718\left(c^{2}\right.$ hitung $)<77.93\left(c^{2}\right.$ tabel), yang berarti bahwa hipotesis alternatif adanya heteroskedastisitas dalam model uji glejser ditolak.

2. Pada persamaan II nilai $R$ Square sebesar 0.147 dengan jumlah data observasi sebanyak 183 , maka besarnya nilai $c^{2}$ hitung $=60 \times 0.147=8.82$, Sedangkan nilai $c^{2}$ tabel dengan $\mathrm{Df}=(60-2)=58$ dan tingkat signifikansi 0.05 maka nilai $c^{2}$ tabel 76.78. Jadi nilai uji glejser $=8.82\left(c^{2}\right.$ hitung $)<76.78\left(c^{2}\right.$ tabel), yang berarti bahwa hipotesis alternatif adanya heteroskedastisitas dalam model uji glejser ditolak.

\subsection{Analisis Substruktural I}

Persamaan Struktural I

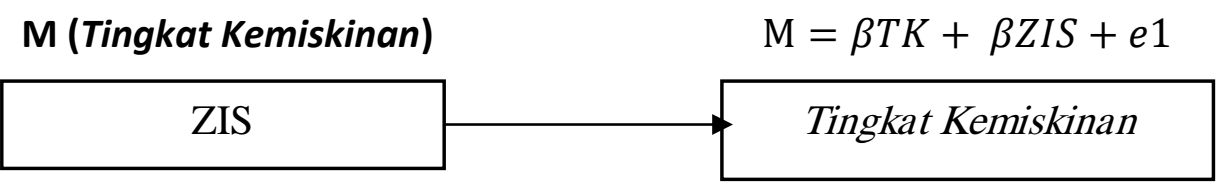

Gambar 1. Pengaruh ZIS Terhadap Tingkat Kemiskinan

Tabel 10. Pengaruh Dana Zakat, Infaq dan Shadaqah (ZIS) terhadap Tingkat Kemiskinan

\begin{tabular}{ll}
\hline Model & Adjusted R Square \\
\hline 1 & 0.405 \\
\hline \multicolumn{2}{c}{ Sumber: Data diolah (2019) }
\end{tabular}

Besarnya angka R Square diatas menunjukkan bahwa pengaruh profitabilitas, likuiditas terhadap Tingkat Kemiskinan sebesar 45\%. Adapun untuk mengetahui kelayan model regresi yang digunakan, ditampilkan angka-angka dari tabel ANOVA, berikut ini: 
Tabel 11. ANOVA dengan Nilai F dan Sig.

\begin{tabular}{lcc}
\hline Model & F & Sig \\
\hline Regression Residual & 13.78 & 0.047 \\
\hline \multicolumn{2}{c}{ Sumber: Data diolah (2019) }
\end{tabular}

Jika F-hitung > F-tabel, maka Ha diterima dan Ho ditolak dan juga sebaliknya F-hitung < F-tabel, maka Ha ditolak dan Ho diterima. Dari hasil perhitungan, diperoleh output dengan F-hitung sebesar $13.78>$ F-tabel sebesar 4.00, yang berarti Ha diterima dan Ho ditolak. Maka, model regresi tersebut sudah layak dan benar. Sehingga dapat ditarik kesimpulan Dana Zakat, Infaq dan Shadaqah (ZIS) secara simultan mempengaruhi Tingkat Kemiskinan. Besar pengaruhnya sebesar $45 \%$ dengan signifikansi $0.0047<\alpha=0.05$. Adapun besar pengaruh variabel lain diluar regresi dihitung dengan rumus: $\left(1-r^{2}\right)=(1-0.450)=0.550$ atau sebesar $55 \%$.

Tabel 12. Pengaruh Dana Zakat, Infaq dan Shadaqah terhadap Tingkat Kemiskinan Coefficients $^{\mathrm{a}}$

\begin{tabular}{|c|c|c|c|c|c|}
\hline \multirow[b]{2}{*}{ Model } & \multicolumn{2}{|c|}{$\begin{array}{l}\text { Unstandardized } \\
\text { Coefficients }\end{array}$} & \multirow{2}{*}{$\begin{array}{l}\text { Standardized } \\
\text { Coefficients }\end{array}$} & \multirow[b]{2}{*}{$\mathrm{T}$} & \multirow[b]{2}{*}{ Sig. } \\
\hline & B & Std. Error & & & \\
\hline (Constant) & 9.609 & .416 & & 23.078 & .000 \\
\hline ZIS & .030 & .015 & -.023 & 1.944 & .057 \\
\hline
\end{tabular}

a. Dependent Variable: T KEMISKINAN

Sumber: Data diolah (2019)

Berdasarkan hasil perhitungan, diperoleh t-hitung sebesar $1.944>\mathrm{t}$-tabel sebesar 1.671, sehingga Ha diterima dan Ho ditolak. Artinya ada pengaruh Dana Zakat, Infaq dan Shadaqah (ZIS) terhadap Tingkat Kemiskinan. Dana Zakat, Infaq dan Shadaqah (ZIS) terhadap Tingkat Kemiskinan berpengaruh sebesar -0.023 atau $-2.3 \%$ dianggap signifikan dengan angka signifikansi $0.057>\alpha=0.05$.

Tabel 13. Dana Zakat, Infaq dan Shadaqah (ZIS), Tingkat Kemiskinan Terhadap Pertumbuhan Ekonomi

\begin{tabular}{cc}
\hline Model $\quad$ Adjusted R Square \\
\hline $1 \quad 0.369$ \\
\hline \multicolumn{2}{c}{ Sumber: Data diolah (2019) }
\end{tabular}

Besarnya angka R Square diatas menunjukkan bahwa Dana Zakat, Infaq dan Shadaqah (ZIS), Tingkat Kemiskinan terhadap Pertumbuhan Ekonomi sebesar 36.90\%. Adapun untuk mengetahui kelayan model regresi yang digunakan, ditampilkan angka-angka dari tabel ANOVA, berikut ini: 
Tabel 14. ANNOVA dengan Nilai F dan Sig.

\begin{tabular}{lcl}
\hline Model & F & Sig \\
\hline Regression Residual & 32.262 & 0.022 \\
\hline \multicolumn{3}{c}{ Sumber: Data diolah (2019) }
\end{tabular}

Jika F-hitung > F-tabel, maka Ha diterima dan Ho ditolak dan juga sebaliknya F-hitung < F-tabel, maka Ha ditolak dan Ho diterima. Dari hasil perhitungan, diperoleh output dengan F-hitung sebesar 32.262 > F-tabel sebesar 4.01, yang berarti Ha diterima dan Ho ditolak. Maka, model regresi tersebut sudah layak dan benar. Sehingga dapat ditarik kesimpulan, Pengaruh Dana Zakat, Infaq dan Shadaqah (ZIS) dan Tingkat Kemiskinan secara simultan mempengaruhi Pertumbuhan Ekonomi. Besar pengaruhnya sebesar $4.01 \%$ dengan signifikansi $0.022<\alpha=0.05$. Adapun besar pengaruh variabel lain diluar regresi dihitung dengan rumus: $\left(1-r^{2}\right)=(1-0.369)=0.631$ atau sebesar $63.10 \%$.

Tabel 15.Pengaruh Dana Zakat, Infaq dan Shadaqah (ZIS) dan Tingkat Kemiskinan terhadap Pertumbuhan Ekonomi

\section{Coefficients $^{\mathrm{a}}$}

\begin{tabular}{lllllll}
\hline & \multicolumn{2}{l}{$\begin{array}{l}\text { Unstandardized } \\
\text { Coefficients }\end{array}$} & \multicolumn{2}{l}{$\begin{array}{l}\text { Standardized } \\
\text { Coefficients }\end{array}$} & \\
\cline { 2 - 6 } Model & $\mathrm{B}$ & Std. Error & Beta & T & Sig. \\
\hline 1 & (Constant) & 1.892 & .633 & & 2.991 & .004 \\
\cline { 2 - 6 } & ZIS & -.013 & .008 & .236 & 1.806 & .042 \\
\cline { 2 - 5 } & T KEMISKINAN & .009 & .063 & -.020 & 1.149 & .023 \\
\hline
\end{tabular}

a. Dependent Variable: P EKONOMI

Sumber: Data diolah (2019)

Jika t-hitung > t-tabel, maka Ha diterima dan Ho ditolak, begitu juga sebaliknya jika thitung < t-tabel, maka Ha ditolak dan Ho diterima. Besarnya angka t-tabel dengan signifikansi $\alpha=0.05$ dan $\mathrm{Df}=(60-2)=58$. Dari ketentuan tersebut diperoleh angka ttabel sebesar 1.676. Pengaruh Dana Zakat, Infaq dan Shadaqah (ZIS) dan Tingkat Kemiskinan secara simultan mempengaruhi Pertumbuhan Ekonomi, sebagai berikut:

1. Berdasarkan hasil perhitungan, diperoleh t-hitung sebesar $1.806>t$ tabel sebesar 1.676, sehingga Ha diterima dan Ho ditolak. Artinya ada pengaruh Dana Zakat, Infaq dan Shadaqah (ZIS) terhadap Pertumbuhan Ekonomi. Dana Zakat, Infaq dan Shadaqah (ZIS) terhadap Pertumbuhan Ekonomi berpengaruh sebesar $0.236=$ $23.60 \%$ dan dianggap signifikan positif dengan angka signifikansi $0.042<\alpha=0.05$.

2. Berdasarkan hasil perhitungan, diperoleh t-hitung sebesar $2.149>t$-tabel sebesar 1.676, sehingga Ha diterima dan Ho ditolak. Artinya ada pengaruh Tingkat Kemiskinan terhadap Pertumbuhan Ekonomi berpengaruh sebesar $0.236=$ 
$23.60 \%$ dan dianggap signifikan positif dengan angka signifikansi $0.023<\alpha=$ 0.05 .

\subsection{Uji Variabel Mediasi Perhitungan Pengaruh}

\section{Pengaruh Langsung (Direct Effect)}

1. Pengaruh Dana ZIS terhadap Tingkat Kemiskinan

$X \rightarrow M=-0.023$

Pengaruh langsung antara Dana ZIS terhadap Tingkat Kemiskinan adalah sebesar -0.023 .

2. Pengaruh Dana ZIS terhadap Pertumbuhan Ekonomi

$X \rightarrow Y=0.236$

Pengaruh langsung antara Dana ZIS terhadap Pertumbuhan Ekonomi adalah sebesar 0.236 .

3. Pengaruh Tingkat Kemiskinan terhadap Pertumbuhan Ekonomi

$\mathrm{M} \rightarrow \mathrm{Y}=0.020$

Pengaruh langsung antara Tingkat Kemiskinan terhadap Pertumbuhan Ekonomi adalah sebesar 0.020 .

\section{Pengaruh Tidak Langsung (Indirect Effect)}

Pengaruh Dana ZIS terhadap Pertumbuhan Ekonomi melalui Tingkat Kemiskinan

$\mathrm{X} 1 \rightarrow \mathrm{M} \rightarrow \mathrm{Y}=[-0.023 \times 0.020]=0.001$

Pengaruh tidak langsung antara Dana ZIS terhadap Pertumbuhan Ekonomi melalui Tingkat Kemiskinan adalah sebesar 0.001.

\section{Pengaruh Total (Total Effect)}

Pengaruh Dana ZIS terhadap Pertumbuhan Ekonomi melalui Tingkat Kemiskinan

$\mathrm{X} 1 \rightarrow \mathrm{M} \rightarrow \mathrm{Y}=[-0.023+0.020]=-0.003$

Jadi total pengaruh Dana ZIS terhadap Pertumbuhan Ekonomi melalui Tingkat Kemiskinan adalah sebesar -0.003 .

\section{Penutup}

Penyaluran Dana Zakat, Infaq, Shadaqah yang berpengaruh negatif terhadap Tingkat Kemiskinan, besar pengaruh Penyaluran Dana ZIS terhadap Tingkat Kemiskinan = 0.023 atau $-2.3 \%$ dengan angka signifikansi $0.057>\alpha=0.05$

Penyaluran Dana Zakat, Infaq, Shadaqah berpengaruh Positif terhadap Pertumbuhan Ekonomi. Besarnya pengaruh Penyaluran Dana Zakat, Infaq, Shadaqah berpengaruh Positif terhadap Pertumbuhan Ekonomi $=0.247$ atau $24.70 \%$ dengan angka signifikansi $0.047<\alpha=0.05$ 
Tingkat Kemiskinan berpengaruh negatif terhadap Pertumbuhan Ekonomi. Besarnya pengaruh Tingkat Kemiskinan berpengaruh positif terhadap Pertumbuhan Ekonomi $=$ -0.020 atau $-2 \%$ dengan angka signifikansi $0.023<\alpha=0.05$.

Tingkat Kemiskinan memediasi pengaruh antara Dana ZIS terhadap Pertumbuhan Ekonomi. Tingkat kemiskinan secara umum akan memediasi potensi ZIS yang tinggi secara signifikan pada tingkat mengurangi beban hidup penduduk menengah kebawah, agar program penyaluran zakat banyak terarah ke pertumbuhan ekonomi secara agregat.

Berdasarkan dari hasil simpulan yang diperoleh, maka penulis menyarankan agar pemerintah dapat melakukan pembaruan pada data ZIS berikut memberikan kemudahan dalam hal akses data, terutama mengenai jumlah dana ZIS per-Provinsi dan Kabupaten/Kota. Selanjutnya untuk pengembangan keilmuan, hendaknya peneliti berikutnya dapat menambah lagi variabel-variabel yang mempunyai korelasi dengan penelitian, khususnya yang berkaitan dengan penyaluran dana ZIS dan pertumbuhan ekonomi di Indonesia.

\section{DAFTAR PUSTAKA}

Adiwarman Karim,. Ekonomi Makro Islam. Kharisma Putra Utama Offset: PT. Rajagrafindo Persada, 2015

Badan Pusat Statistik. 2011. Laporan Perekonomian Indonesia 2011. Jakarta:

Bahri S, Andi. 2016. Zakat Sebagai Instrumen Pembangunan Ekonomi Kesejahteraan Ummat. Li Falah: Jurnal Studi Ekonomi dan Bisnis Islam Volume I, Nomor 2, Desember 2016

Firdaus, Muhammad, Irfan Syauqi Beik, Tonny Irawan, Bambang Juanda. 2012. Economic Estimastion and Determinations of Zakat Potential in Indonesia. IRTI Working Paper.

Ghani, Abdul Samsudin. Pembangunan ekonomi islam : perspektif Malaysia.2004

Haryanto, Tomy. 2013. Economic Development Analysis. 2 (3): 151

Imam Ghazali, Aplikasi Analisis Multivariete dengan Program IBM SPSS 23, Cetakan keVIII, (Badan Penerbit Universitas Diponegoro: 2016),

Meutia, I. Shariah Enterprise Theory Sebagai Dasar Pengungkapan Tanggungjawab Sosial Untuk Bank Syariah. Disertasi. Program Pascasarjana. Universitas Brawijaya. Malang: 2010

Munandar, Eris, Mulia Amirullah, and Nila Nurochani. "Pengaruh Penyaluran Dana Zakat, Infak Dan Sedekah (ZIS) dan Pertumbuhan Ekonomi Terhadap Tingkat Kemiskinan." Al-Mal 1.1 (2020)

Naf'an. 2014. Ekonomi Makro Tinjauan Ekonomi Syari'ah.Yogyakarta: Graha Ilmu

Noor, Juliansyah. "Metodologi Penelitian: Skripsi, Tesis, Disertasi, dan Karya Ilmiah". (Jakarta. Penerbit Kencana Prenada Media Group. 2011) 
Qardhawi, Yusuf. Fiqih Zakat . Beirut: Muassasah ar Risalah 2005. Spektrum Zakatdalam Membangun Ekonomi Kerakyatan. Jakarta: Zikrul Media Intlektual Terjemahan Sari Natulita, Lc, 2000

Romdhoni, Abdul Haris. 2017. Zakat Dalam Mendorong Pertumbuhan Ekonomi Dan Pengentasan Kemiskinan. Jurnal IImiah Ekonomi Islam vol. 03. No. 01, Maret 2017

Santoso, Singgih. Menguasai SPSS 22 From Basic to Expert Skills, PT. Elek Media Komutindo, Jakarta: 2015

Sarea, Adel. 2012. Zakat as a Benchmark to Evaluate Economic Growth : an Alternative Approach. Vol 3

Silva, Engla Desnim dkk 2013. Analisis Pertumbuhan Ekonomi, Investasi, dan Inflasi di Indonesia. Vol 1 (2): 225

Suprayitno, Eko dkk.2013. The Impact of Zakat on Aggregate Consumtion in Malaysia. Vol 9 (1)

Widarjono, Agus. Analisis Statistika Multivariat Terapan, Yogyakarta: Unit Penerbit dan Percetakan Sekolah Tinggi Ilmu Manajemen YKPN 2010

www.baznas.go.id 